South African triangulation in terms of the European Datum. Russian triangulation, known to exist but not published, could carry the same datum to Vladivostok, and a gap of 1,000 miles in Persia is all that prevents it extending to Singapore. Radar measures, of geodetic accuracy, between Europe, Greenland and America will link the European and American datums within a fow years, and triangulation from the latter already extends well into South America. The days of separate, isolated national surveys are passing.

A paper by H. A. Stamers Smith gave a useful summary of the present state of geodetic triangulation in Nigeria, where primary traverse has in places been very successfully used as a substitute for triangulation. The misclosures of ten such traverses are given, averaging about 1 in 100,000 in distances of 100-200 miles.

A paper by Col. R. C. A. Edge described work done by the Ordnance Survey with eloctronic computing. Traverse and levelling computations are a heavy item in the ordinary work, but, varying much in detail, require a high proportion of 'arranging' for pure computation. They are therefore more suited to punch-card mothods using a small calculator (such as the I.B.M. 626) than to a large storage computer. An I.B.M. 626 has recently been installed at the Ordnance Survey. Photogrammetric computations, another heavy item, are more uniform but mathematically more complex. They are suitable for a large computer, and for some time they have been programmed for, and successfully computed by, $A C E$. They are now being programmed for $D E U C E$.

Space does not admit mention of the remaining papers, but all are of value in their own spheres. These Survey Conferences are held at four-yearly intervals, and provide a most welcome opportunity for surveyors from all over the Commonwealth to exchange ideas and to renew friendships. The papers presented at previous conferences, and the resulting discussions, have been published by H.M. Stationery Office, and it is hoped that a 1955 volume will soon be published also.

G. BOMTORD

\section{INTERNATIONAL BIOMETRIC SYMPOSIUM IN BRAZIL}

$\mathrm{T}$

HE Biometric Society, which now forms the Biometric Section of the International Union of Biological Sciences, is endeavouring to stimulate the teaching and use of good statistical practices in biology in many parts of the world. As part of this programme, an international biometric symposium was held in Campinas, Brazil, during July 4-9. The University of São Paulo was host to the symposium, and a committee of the University Seminario de Estatistica, with Dr. C. G. Fraga (Institute of Agronomy, Campinas) as secretary, handled local arrangements; financial assistance was received from ten different governmental and non-governmental organizations. The ninety-eight statisticians and biologists attending included sixty-two from Brazil, eight from other Latin American countries, fourteen from the United States, five from Great Britain, seven from other European countries, and two from Asia. The foreign visitors will long remember the hospitality of their Brazilian hosts.
The president of the Society, Prof. W. G. Cochran (Johns Hopkins University), took as the subject of his address the 1954 trial of the Salk poliomyelitis vaccine in the United States, focusing attention on the design of the investigation rather than upon the outcome. He said that in 'placebo areas' children who received the vaccine were matched by controls receiving a similar injection of a placebo, while in other parts of the country the only controls were younger and older uninoculated children. The difference between case-rates in inoculated and control children was apparently greater in the placebo areas. His suggested explanation was that natural immunity was lower in the homes of children whose parents consented to their inclusion in the trial, a consent necessary in the placebo areas for all participators but elsewhere only for the inoculated.

In the afternoon, Sir Ronald Fisher (University of Cambridge) described the contribution of biometry to plant improvement, with special reference to experimental design, the analysis of genetic models involving large numbers of Mendelian factors that cannot be individually identified, and classical Mendelian genetics. Prof. E. R. Dempster (University of California) then discussed genetic models in animal breeding. Shorter papers on biometrical genetics by Prof. F. G. Brieger (Agricultural College, Piracicaba) and Dr. H. Kalmus (University College, London) related to autogamic populations and heterotic genes in plant geneties and to cyclomorphosis, respectively.

Two sessions on experimental design were held on July 5. Dr. S. C. Pearce (East Malling Research Station) showed that difficulties of adequate replication with perennial crops restrict the experimenter to very simple designs. A compensation is that relation. ships between many concomitant measurements can be studied. He illustrated the balancing of treatments so that one set of trees can be used for two or more consecutive investigations. E. Amaral (Institute of Agronomy, Pelotas) discussed missing yields and other problems in the analysis of sugarcane experiments. The design and analysis of coffee experiments at the Campinas Institute of Agronomy were reviewed by Dr. A. Conagin and Dr. Fraga, who showed how modern design had improved the quality of information obtainable in research on this crop. In a more theoretical paper, Dr. F. Pimentel Gomes (University of São Paulo) spoke of the use of the Mitscherlich equation in analysing fertilizer experiments on sugar-cane. In the afternoon, Miss G. M. Cox (University of North Carolina) surveyed recent work in the theory of experimental design; her paper was of particular interest for its mention of special designs for estimating optimal conditions, including the new category of rotatable designs. Dr. W. J. Youden (Bureau of Standards, Washington, D.C.) then gave a graphic account of how types of design developed by biologists are now assisting research on physical problems. With remarkable clarity and humour, he illustrated the adaptation of designs to situations in which the block size is predetermined; or, at most, two replications are wanted; or some treatments are to be chosen after part of the experiment was complete; or in which instrumental drift is a serious factor. On the follow. ing day, during a visit to the Agricultural College at Piracicaba, nembers held a discussion on experimental design for perennial crops. 
On July 7, Prof. P. G. Homeyer (Iowa State College) summarized experience on sources of variation in feeding experiments with chicken, cattle and pigs, and its use in designing new experiments; he emphasized particularly the danger of neglecting variation between pens. Dr. G. L. Rocha (Brazil) and Dr. G. O. Mott (Purdue University) reviewed the technique and interpretation of pasture experiments in Brazil and the United States, respectively, after which Prof. A. Linder (University of Geneva) described an experiment on the grazing times of cows permitted to choose between differently treated plots. In the afternoon session, on sampling tech. niques, Dr. M. H. Hansen (United States Bureau of the Census) discussed the control of errors of response in sample surveys. Recent work on the theory and practice of estimating fish catches around the Indian coast was then described by Dr. P. V. Sukhatme (Food and Agriculture Organization). Prof. J. Nieto de Pascual (Bureau of Statistics, Mexico) described a survey of national morbidity in Mexico, and Prof. W. L. Stevens (University of São Paulo) presented an account of recent work on the sample estimation of the coffee harvest, a problem complicated by a biennial cycle of bearing. The session ended with a paper from Dr. E. Cansado (Interamerican Statistical Centre, Santiago, Chile) on new proofs of theorems on sampling from a finite population.

After a morning visit to the State Institute of Agronomy at Campinas, the afternoon of July 8 was given to papers on bioassay. Dr. C. I. Bliss (Connecticut Agricultural Experiment Station) showed general methods for obtaining confidence intervals for estimates of relative potency, and then illustrated how these could be adapted to various assay techniques in the "U.S. Pharmacopeia". Dr. D. J. Finney (University of Aberdeen) presented five models relating to correlations of residual error and residual effects of previous doses in cross-over and singlesubject assays, and explained the statistical analysis appropriate to various designs. Dr. P. Mello Freire (Institute of Biology, São Paulo) described the analysis and interpretation of three 'complement fixation' assays. Finally, several questions on bio-assay, with special reference to the assay of snake venom, were submitted to a panel for discussion.

The first of four papers on medical statistics on July 9 , that by Dr. J. O. Irwin (London School of Hygiene and Tropical Medicine), related to an experiment conducted in Singapore with human subjects to assess the influence of air movement, temperature, humidity, clothing and other factors on sweat-rate and other physiological measurements. An interesting application of covariance analysis was shown by Dr. J. N. Manceau (Public Health Service, Pará) in his account of a comparison between two antihelminthics for the control of nematode parasites in seventy-four Belém children. Dr. A. E. Brandt (United States Atomic Energy Commission) described briefly an investigation into the clinical effects of two different very high-voltage sources proposed for the treatment of cancers that are frequently incurable by conventional radiotherapy; he then considered the problems of performing a clinical trial on one type of cancer, with adequate random allocation of patients to the two treatments yet within the limits imposed by medical ethics. The final paper, by Prof. A. Vessereau (Sorbonne), consisted of an interesting application of discriminant function analysis to the diagnosis of medical and surgical cases of jaundice from electrophoretic analysis of serum proteins.

One of the most satisfactory features of the sym. posium was the lively discussion that followed almost every paper : the variety of questions and comments, and the number of people taking part, proved that the holding of the symposium was fully justified. Moreover, Brazilian science will continue to benefit from this venture, for it provided the impetus for the immediate formation of a Brazilian Region of the Biometric Society (which already has more than fifty members) and also of a Brazilian Genetical Society.

D. J. Finney

\section{DESIGN OF ELECTRONIC DEVICES FOR PRODUCTION}

A SUMMER school on the role of the trained scientist in the design of electronic devices for production was held at the Services Electronics Research Laboratories in Baldock and Harlow during September 20-23. More than sixty university and technical-college professors and lecturers attended. Accommodation was provided by Emmanuel College, Cambridge, and transport to and from the Laboratories was by motor coach.

The first speaker was Mr. A. J. Young (English Electric Valve Co.), who surveyed the recent developments in special valves. $\mathrm{He}$ directed attention particularly to one of the functions of management in the device industry, namely, to decide to pursue a particular line of development. The scientific judgment required to execute this function to the best advantage is an increasing need in the industry, and it should be the object of the universities and technical colleges to bring forward scientists having good understanding of their subject and, as a result, good judgment regarding device development. The next speaker was Mr. D. S. G. Lewis (officer in charge of the extension of the Services Electronics Research Laboratory at Harlow), whose subject was mag. netrons, and he gave a résumé of the problems facing the designer after fifteen years of development. In particular, he directed attention to the complicated nature of the device, in which the variation of any one parameter alters the effect of every other one. Mr. Lewis sketched the problems arising in the manufacture of magnetrons, giving special attention to the close limits imposed at very high frequencies. The final speaker on the first day was Dr. J. M. Dodds (Metropolitan-Vickers Electrical Co., Ltd.), his subject being high-power klystrons. He explained why the klystron is preferred to the magnetron for certain purposes, and described the design and manufacture of a klystron suitable for driving a very high-power linear accelerator. During this first day examples of modern valves were exhibited, many valve firms contributing samples of their latest designs. In the afternoon, Dr. H. A. H. Boot, one of the inventors of the multi-cavity magnetron, supervised a demonstration of micro-wave valve-making techniques.

The second day of the school opened with a discussion of methods of generation of millimetre waves, given by Mr. P. O. Hawkins (Services Electronics Research Laboratory). Mr. Hawkins, in addition to surveying the field, gave special attention to a floating drift tube klystron capable of delivering 10-20 W. at a wave-length of $8 \mathrm{~mm}$. He was followed by $\mathrm{Dr}$. 